\title{
A method for the measurement of particulate $C$ and $P$ on the same filtered sample
}

\author{
G. G. Lampman, N. F. Caraco*, J. J. Cole \\ Institute of Ecosystem Studies, Box AB, Millbrook, New York 12545, USA
}

\begin{abstract}
There is substantial interest in measuring C:P ratios in aquatic systems because these particulate ratios may influence food quality of phytoplankton to zooplankton grazers. In most analyses $\mathrm{C}$ is measured by dry combustion using a $\mathrm{CN}$ analyzer requiring that $\mathrm{P}$ be measured on a separate sample. We show for marine and freshwater phytoplankton cultures and naturally occurring seston that $\mathrm{C}$ can be measured by a variation of the same wet-persulfate digestion method frequently used for $\mathrm{P}$ analysis, allowing $\mathrm{C}$ and $\mathrm{P}$ to be measured on the same filter. Over a large range of $\mathrm{C}$ values (1 to $40 \mu \mathrm{mol} \mathrm{C}$ filter $^{-1}$ ), the persulfate method for measuring $\mathrm{C}$ gave the same $\mathrm{C}$ value for lake seston, estuarine seston, and marine and freshwater phytoplankton cultures as high temperature dry combustion on a Carlo-Erba $\mathrm{CN}$ analyzer. For $\mathrm{C}$, the wet digestion method is much less expensive than the dry combustion method in terms of both equipment and per-sample materials costs. Further, the persulfate method is more precise $(\mathrm{CV}=3 \%)$ than the dry combustion method $(\mathrm{CV}=12 \%)$ for the measurement of $\mathrm{C}$. This greater precision of $\mathrm{C}$ measurement, and the fact that $\mathrm{C}$ and $\mathrm{P}$ are measured on the same sample, means that small differences in C:P ratios can more readily be detected.
\end{abstract}

KEY WORDS: Particulate $\cdot$ Phosphorus $\cdot$ Carbon $\cdot$ Method $\cdot$ C:P ratio

\section{INTRODUCTION}

Carbon to phosphorus ratios (C:P) in aquatic ecosystems are an important indicator of food quality (Sterner et al. 1997, Elser et al. 1998) and a critical determinant of oceanic export production (Sambrotto et al. 1993, Jingfeng et al. 2000). Most methods for particulate C analysis were developed over 30 yr ago (Maciolek 1962, Menzel \& Vaccaro 1964, Wangersky \& Gordon 1965, and others), and have since been altered and improved (e.g., Gordon \& Sutcliffe 1974, Sharp 1974, Hilton et al. 1986, Nakajima 1986, McDowell et al. 1987, and others). All of these methods begin with chemical or physical oxidation to convert all forms of $\mathrm{C}$ to $\mathrm{CO}_{2}$, followed by its subsequent analysis using gas (GC) or liquid chromatography, or through the use of infrared $\mathrm{CO}_{2}$ analyzers. In various versions, the oxidation step involves dry combustion in an ampoule or

*Corresponding author. E-mail: caracon@ecostudies.org
CHN analyzer (American Public Health Association 1992), wet oxidation using persulfate or chromic acid (Strickland \& Parsons 1968) or other oxidizing agents, or irradiation of samples with ultraviolet light (American Public Health Association 1992). Total P (TP) analysis has generally used a wet persulfate digestion since Menzel \& Corwin (1965) introduced this method. Phosphorus is converted to $\mathrm{PO}_{4}$ and analyzed colorometrically on a spectrophotometer or autoanalyzer (American Public Health Association 1992).

Following the recommendation by Strickland \& Parsons (1967) to analyze $\mathrm{C}$ using $\mathrm{CH}$-analyzers when available, the $\mathrm{C}$ in seston has generally been measured using these instruments. When C:P ratios are to be evaluated, replicate seston samples for $\mathrm{P}$ undergo a separate, persulfate digestion and are analyzed by colorimetric techniques on separate filters (American Public Health Association 1992). This use of separate samples to determine C:P ratios increases the cost of analysis as well as the variability of the results because of slight differences in the amount of material on sepa- 
rate filters. Determined this way, the C:P ratio includes the variance resulting from sample collection on separate filters and the analytical variance of both methods.

In 1993, Malley et al. introduced a method that could determine $\mathrm{C}, \mathrm{N}$, and $\mathrm{P}$ on the same sample, but it required the use of a near-infrared spectroscope, expensive equipment not normally associated with aquatic research. Recently Raimbault et al. (1999) introduced a new method based on a basic persulfate digestion for the simultaneous determination of particulate $\mathrm{C}, \mathrm{N}$, and $\mathrm{P}$ on a single filter. While this method seems efficient at $\mathrm{N}$ and $\mathrm{C}$ digestion, we were concerned that it may not hydrolyze some forms of P. Polyphosphates may be especially difficult to hydrolyze under these conditions.

We present a wet digestion technique, which is a variation of the standard TP digestion of Menzel \& Corwin (1965). We compare C measured by this technique with that on a Carlo-Erba $\mathrm{C}: \mathrm{N}$ analyzer. Further, we compare $\mathrm{P}$ determination by this method with a recently proposed basic persulfate digestion method (Raimbault et al. 1999) and with a dry digestion method developed for sediments (Anderson 1976). Lastly, we show some initial results for particulate $\mathrm{N}$ determination in which we perform a redigestion under basic conditions of the original acid digest.

\section{MATERIALS AND METHODS}

The digestion is a variation of the persulfate method that Menzel \& Corwin (1965) developed for TP. The procedure involves 4 steps: (1) collecting particulate matter on glass fiber filters; (2) digesting filters in sealed $20 \mathrm{ml}$ serum vials containing $10 \mathrm{ml}$ of $1 \%$ persulfate in an autoclave for $2.5 \mathrm{~h}$ at $120^{\circ} \mathrm{C}_{i}$ (3) extracting the $\mathrm{CO}_{2}$ in the head space and analyzing it using a GC equipped with a Thermal Conductivity Detector (TCD); and (4) analyzing the digested $\mathrm{P}$ as $\mathrm{PO}_{4}$ in the aqueous portion by spectophometry.

Glass fiber filters (Whatman GF/F, $25 \mathrm{~mm}$ ) were prepared for use with samples and standards by soaking for $1 \mathrm{~h}$ in $0.1 \mathrm{~N} \mathrm{H}_{2} \mathrm{SO}_{4}$ and rinsing with nanopure water. These filters remained intact during the digestion, eliminating the need to filter the digestate for $\mathrm{PO}_{4}$ analysis.

- Standards-Glucose, L-serine and tripolyphosphate mixed standards were prepared in concentrations that allowed $200 \mu \mathrm{l}$ aliquots to be pipetted directly onto, and be absorbed by, prepared glass fiber filters.

- Seston-Surface water was collected from Chodikee Lake, Ulster County, New York, USA (dominated by Cyanobacteria), and at a number of sites along the freshwater tidal portion of the Hudson River Estuary in
11 HDPE bottles. Aliquots of 100 to $200 \mathrm{ml}$ were filtered through glass fiber filters that had been cleaned as above.

- Phytoplankton cultures-Three types of phytoplankton cultures were used. The marine diatom Ditylum brightwellii was purchased from Provasoli-Guillard National Center for Culture of Marine Phytoplankton (Bigelow Laboratory, ME, USA; CCMP \#359) and grown in a 1/10 dilution of Stosch media (von Stosch \& Drebes 1964). Cultures of a freshwater chrysophyte (Ochromonas spp.) and chlorophyte (Selenastrum capricornutum) were purchased from Carolina Biological Supply (Burlington, NC, USA) and cultured in lake water enriched with $\mathrm{N}, \mathrm{P}$, and bicarbonate in Redfield ratio (Redfield 1958) as described in Caraco \& Miller (1998). Aliquots of 10 to $40 \mathrm{ml}$ were filtered as for seston (above).

- Zooplankton samples - Samples were obtained by hauling a $120 \mu \mathrm{m}$ plankton net through Upton Lake, Dutchess County, New York. Once collected, the zooplankton samples were not filtered. Rather, known numbers were picked individually using an Irwin loop and placed directly into the serum vials.

For the filtration of seston and phytoplankton, we used a vacuum of no greater than 0.65 atmospheres (61 $\mathrm{kPa})$, and the filters were generally dried before running as required by the Carlo-Erba analyzer. Additionally, however, samples can be frozen for future analysis or run immediately because dried samples are not necessary in a wet digestion procedure. A filtered volume of 100 to $200 \mathrm{ml}$ worked well for lake and river seston, while 10 to $40 \mathrm{ml}$ was sufficient for phytoplankton cultures. If larger volumes of water need to be filtered, or samples have high DOC concentrations, tests should be run to evaluate DOC adsorption to the glass fiber filters (Abdel-Moati 1990).

Procedure. Samples and standards were digested by placing filters in $20 \mathrm{ml}$ serum vials (Wheaton \#223687) containing $10.0 \mathrm{ml}$ of $1 \%$ low $\mathrm{N}$ potassium persulfate (Fisher Scientific ID \#P282-500; $10.0 \mathrm{ml}$ ), sealed by crimping on aluminum rings (Kimble \#73822A-20) containing butyl rubber septa (Tekmar \#14-4385-043) and autoclaved for $2.5 \mathrm{~h}$ at $120^{\circ} \mathrm{C}$. Using an autoclave with a slow pressure release is important since a rapid drop in pressure may cause the vials to leak, thus altering results.

Once samples reached room temperature the carbon headspace samples were extracted with a $20 \mathrm{ml}$ syringe equipped with a 2-way stopcock and needle. With the stopcock open, the needle was inserted through the septa, the plunger drawn back to $15 \mathrm{ml}$, the stopcock closed, and the plunger allowed to draw back to neutral, approximately $11 \mathrm{ml}$. These headspace samples were then run on a Shimadzu GC-8A equipped with a thermal conductivity detector with the 
injector/detector at $110^{\circ} \mathrm{C}$ and the column at $44^{\circ} \mathrm{C}$. The remaining aqueous portion of the sample, containing the persulfate digested particulate $\mathrm{P}$ sample, was fully oxidized to $\mathrm{PO}_{4}$. After allowing the sample to settle, $3 \mathrm{ml}$ of liquid was extracted. This subsample was then analyzed colorometrically following the method of Murphy \& Riley (1962) using a Shimadzu UV-160 spectrophotometer with a $1 \mathrm{~cm}$ spec cell and the wavelength set to measure at $880 \mathrm{~nm}$.

For a limited number of samples, the possibility of total $\mathrm{N}$ determination was tested by redigesting the $1 \%$ persulfate digested sample in basic persulfate following the method of D'Elia et al. (1977). The digestion reagent was prepared by dissolving $2.0 \mathrm{~g}$ of low $\mathrm{N}$ potassium persulfate and $1.0 \mathrm{~g}$ of low $\mathrm{N}$ sodium hydroxide (Fisher Scientific ID \#5318-100) in $50 \mathrm{ml}$ of nanopure water. Screw top test tubes containing $3 \mathrm{ml}$ of subsamples were then spiked with $0.45 \mathrm{ml}$ of this digestion reagent, capped and autoclaved for $2.5 \mathrm{~h}$ at $120^{\circ} \mathrm{C}$. The resulting nitrate was measured by the sulfanilamide method (American Public Health Association 1992) modified for an Alpkem Autoanalyzer (Alpkem Corporation 1992).

To compare the digestion efficiency of our carbon method, the peak areas derived from persulfate digested glucose/L-serine standards run using our method were compared with acidified bicarbonate standards in the same concentration range analyzed using the method of Stainton (1973). Both sets of stan-
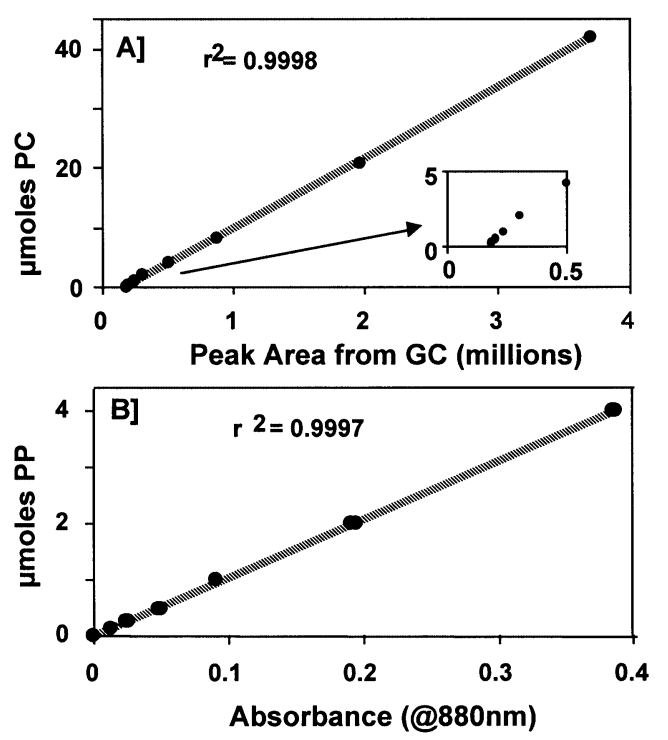

Fig. 1. Standard curves for the measurement of (A) particulate $\mathrm{C}(\mathrm{PC})$ and $(\mathrm{B})$ particulate $\mathrm{P}(\mathrm{PP})$ using the $1 \%$ persulfate digestion technique. For (A), the equation for the line is $\mu \mathrm{mol}$ $\mathrm{C}=1.12 \times 10^{-5} \times$ peak area $-1.79 ; \mathrm{r}^{2}=0.999$. The inset box shows the relation at very low amounts of particulate $C$ ( 0 to $5 \mu \mathrm{mol} \mathrm{C}$ per filter). For (B), the equation for the line is $\mu \mathrm{mol}$ $\mathrm{P}=10.38 \times$ absorbance $+0.0068 ; \mathrm{r}^{2}=0.999$. GC: gas chromatography dards were run on the same Shimadzu GC (GC-8A) equipped with a thermal conductivity detector and set up as described above. Similarly, replicate particulate C samples, as phytoplankton and seston, were run using our method and on a Carlo-Erba C-N-S elemental analyzer where $\mathrm{C}$ was oxidized at $1000^{\circ} \mathrm{C}$, and resulting peaks were compared with a known mass of acetanilide standard to determine mass.

To evaluate TP digestion efficiency of our method, replicate seston samples from the Hudson River Estuary were run using our persulfate technique and compared with those run using a very rigorous TP ignition method designed for sediment and biogenic materials by Andersen (1976). In this method, samples are placed in a porcelain crucible and ignited in a muffle furnace $\left(550^{\circ} \mathrm{C}\right.$ for $\left.1 \mathrm{~h}\right)$ followed by boiling in $1 \mathrm{~N} \mathrm{HCl}$ for $15 \mathrm{~min}$ and colorimetric determination of P. Replicate Hudson River seston samples and tripolyphosphate (Sigma ID \#T5883) standards analyzed using our technique were also compared with those analyzed using the basic persulfate digestion method designed by Raimbault et al. (1999), where samples are autoclaved at $120^{\circ} \mathrm{C}$ for $30 \mathrm{~min}$ in a basic solution of $0.75 \%$ persulfate.

\section{RESULTS}

Over a wide range of C (0.26 to $42 \mu \mathrm{mol}$ per vial) and $\mathrm{P}$ (0.125 to $4.0 \mu \mathrm{mol}$ per vial) masses, standards were linear for both analyses (Fig. 1). Most C analysis runs were done with standards ranging from 2.1 to $21.0 \mu \mathrm{mol}$. The variability in peak height of these standards, both within and between runs, was low and inversely correlated to $\mathrm{C}$ mass. For samples $<2 \mu \mathrm{mol}$, more than 10 individual samples are needed so that the $95 \%$ CI does not exceed $10 \%$ of the mean value (Fig. 2). For samples $>20 \mu \mathrm{mol}$, there is a 95\% certainty that the mean of duplicates is within $10 \%$ of the true mean. Blank filters (no organic $\mathrm{C}$ added) produced a relative peak height (mean peak height $=296000$; coefficient of variation $[\mathrm{CV}]=22.6) 29 \%$ lower than the lowest $(2.1 \mu \mathrm{mol})$ standard (mean peak height = $419000 ; \mathrm{CV}=12.1$ ).

To evaluate the carbon digestion efficiency of our persulfate GC technique, the results of natural samples run using our GC technique were compared with those run on a high temperature $\left(1000^{\circ} \mathrm{C}\right)$ dry combustion Carlo-Erba C-N-S elemental analyzer using an acetanilide standard. For sample filters containing from 1 to $40 \mu \mathrm{mol}$ no significant difference was found between the 2 methods (Table 1, Fig. 3). In a linear regression between the 2 methods, the intercept $(0.55 \mu \mathrm{mol} \pm$ 0.6 [SE]) was not significantly different from $0(\mathrm{p}>$ $0.35)$ and the slope $(0.983 \pm 0.6[\mathrm{SE}])$ of the regression 


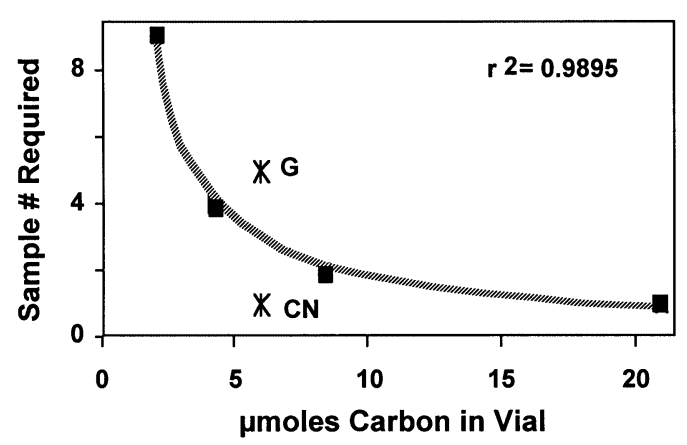

Fig. 2. Replication analysis for the $1 \%$ persulfate method to measure $\mathrm{C}$. The heavy line with solid square points shows the number of samples required so that the $95 \%$ CI does not exceed $10 \%$ of the mean, as a function of the amount of $\mathrm{C}$ (as glucose/L-serine mixed stock standards). The equation for the line is $y=16.74 \times x^{-0.95} ; \mathrm{r}^{2}=0.989$. Asterisks show the same calculation for Ditylum brightwellii cultures at one C level run on the Carlo-Erba CHN (CN) analyzer and on the gas chromatograph (GC) using the $1 \%$ persulfate method

was not significantly different from 1.0 ( $t$-test, $\mathrm{p}<0.01$ ). This shows that in the 1 to $40 \mu$ mol range, digestion efficiency in persulfate is equivalent to that in the high temperature $\mathrm{CN}$ analyzer. Further, it shows that there is not a significant systematic bias between the 2 methods.

Any variation for individual samples from the 1:1 line could have been caused by analytical error or actual differences in the amount of material on replicate filters. Filter replicates may vary in the amount of material filtered, inclusion of rare particles on one filter, or the clumping of phytoplankton or suspended materials within the sample. This last possibility may be a particular problem for the seston filters where inclusion of a single zooplankton on one filter and not the other may alter the results.

The variability in carbon analysis using our persulfate digestion GC method was also compared with that using the Carlo-Erba CN analyzer. To do this, a culture of the marine diatom Ditylum brightwellii was used.

Table 1. Equations of the line for replicate samples run using our gas chromatograph technique ( $x$-axis) and a combustion $\mathrm{CN}$ analyzer ( $y$-axis)

\begin{tabular}{|lcccr|}
\hline & $\mathrm{r}^{2}$ & Slope & $\begin{array}{c}\text { Slope } \\
(95 \% \mathrm{CI})\end{array}$ & $y$-intercept \\
\hline Chrysophytes & 0.92 & 1.01 & $0.83-1.18$ & -1.62 \\
Chlorophytes & 0.88 & 0.97 & $0.76-1.18$ & 1.34 \\
Diatoms & 0.97 & 0.97 & $0.88-1.07$ & -0.24 \\
Lake seston & 0.71 & 0.88 & $0.57-1.19$ & 4.21 \\
Estuarine seston & 0.93 & 1.09 & $0.75-1.42$ & -0.53 \\
All combined & 0.90 & 0.98 & $0.91-1.02$ & 0.55 \\
\hline
\end{tabular}

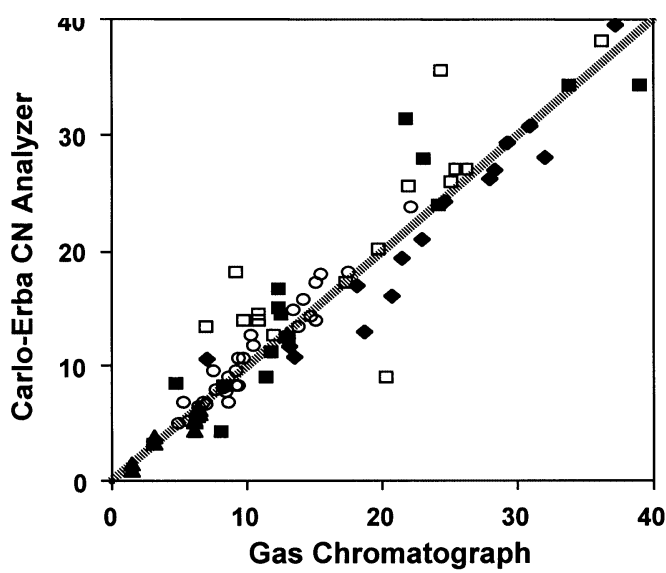

Fig. 3. Comparison of $\mathrm{C}$ analyzed by wet digestion and run on a gas chromatograph technique (our technique) with the traditional combustion CN analyzer. Replicate samples of phytoplankton and seston were compared: chrysophytes $(\bullet)$; chlorophytes $(\mathbf{\square})$; diatoms $(\mathbf{\Lambda})$; lake seston $(\square)$; and estuarine seston (o). The line is the 1:1 $(y=x)$ line. Actual regression equations are presented in Table 1. Results are plotted as total Cmeasured in $\mu \mathrm{mol}$

These cells do not form clumps; therefore, replicate filters should have similar amounts of material. The Carlo-Erba technique was found to be 4 times more variable than the GC technique in the sample size we tested (Table 2). The precision of the GC technique means that fewer replicates are necessary when looking for differences in samples with very similar carbon concentrations, thus saving time and expense.

To determine the efficiency of the persulfate digestion on particulate phosphorus, replicate samples of seston from the Hudson River Estuary were run using our $1 \%$ persulfate method and an ignition method for TP in lake sediments (Anderson 1976). No significant difference was found between the 2 methods. The intercept $(0.01 \mu \mathrm{mol} \pm 0.03$ [SE] $)$ was not significantly different from 0 , nor was the slope $(0.951 \pm 0.14$ [SE]) of the regression of micromoles $\mathrm{P}$ (ignition method) as a function of micromoles $\mathrm{P}$ (persulfate method) significantly different from 1.0 ( $t$-test, $\mathrm{p}<0.0001)$. This shows that in the 0.05 to $0.3 \mu \mathrm{mol}$ range, there is complete oxidation of all forms of $\mathrm{P}$ in $10 \mathrm{ml}$ of $1 \%$ persulfate.

The digestion efficiency of a new CNP method proposed by Raimbault et al. (1999) and our $1 \%$ persulfate method was also tested on polyphosphate standards and Hudson River Estuary seston. Our $1 \%$ persulfate method digested over $90 \%$ of the polyphosphate while the Raimbault et al. (1999) method digested under 20\% 
Table 2. Variability of data obtained by the Carlo-Erba combustion CN analyzer compared with the gas chromatograph (GC) method using 8 replicate diatom (Ditylum brightwellii) samples for each method. Phosphorus values were derived from the same sample run for $\mathrm{C}$ on the $\mathrm{GC}$ providing $\mathrm{C}: \mathrm{P}$ ratios close to data obtained by Redfield (1958) with very low variation, while C:P ratios provided by separate $\mathrm{C}$ and $\mathrm{P}$ (where $\mathrm{C}$ is run on a $\mathrm{CN}$ analyzer) analysis yielded much larger variability. CV: coefficient of variation

\begin{tabular}{|c|c|c|c|c|c|}
\hline & \multicolumn{2}{|c|}{$\mathrm{C}(\mu \mathrm{mol})$} & \multirow{2}{*}{$\begin{array}{c}\mathrm{P}(\mu \mathrm{mol}) \\
1 \% \text { persulfate }\end{array}$} & \multicolumn{2}{|c|}{$\mathrm{C}: \mathrm{P}$ ratio } \\
\hline & $\mathrm{CN}$ analyzer & $\mathrm{GC}$ & & $\mathrm{CN}$ analyzer & GC \\
\hline & 6.30 & 6.58 & 0.065 & 96.6 & 100.9 \\
\hline & 5.92 & 6.59 & 0.067 & 88.4 & 98.4 \\
\hline & 4.99 & 6.11 & 0.063 & 79.3 & 97.1 \\
\hline & 5.55 & 6.21 & 0.063 & 88.2 & 98.7 \\
\hline & 5.33 & 6.10 & 0.064 & 83.5 & 95.6 \\
\hline & 4.39 & 6.09 & 0.062 & 72.0 & 99.8 \\
\hline & 6.31 & 6.24 & 0.062 & 102.6 & 101.5 \\
\hline & 6.11 & 6.31 & 0.065 & 93.7 & 96.8 \\
\hline Mean & 5.61 & 6.28 & 0.064 & 88.0 & 98.6 \\
\hline Range & $4.39-6.31$ & $6.09-6.59$ & $0.061-0.067$ & $72.0-102.6$ & $95.6-101.5$ \\
\hline $\mathrm{CV}$ & 12.18 & 3.25 & 3.19 & 11.1 & 2.1 \\
\hline
\end{tabular}

compared with sodium phosphate standards. Further, when replicate samples of Hudson River seston were run using both methods the results were significantly different (paired $t$-test; $\mathrm{p}<0.001$ ). The Raimbault et al. (1999) method returned particulate phosphorus values averaging $55 \%$ lower (range 28 to $72 \%$ ) than those digested in $1 \%$ persulfate.

When 10 individual Daphnia spp. were digested in $1 \%$ persulfate, without filters, their resulting C:P ratios were lower, but similar to those found by Anderson \& Hessen (1991), and the variability was small (mean $\mathrm{C}: \mathrm{P}=53.75 ; \mathrm{CV}=8.2$ ) (Table 3). Attempts to digest

Table 3. Results from 9 replicate samples of 10 individual zooplankton (Daphnia spp.) digested in each vial using the $1 \%$ persulfate digestion technique with the resulting $\mathrm{C}$ and $\mathrm{P}$ masses. The resulting C:P ratios are similar to those of Anderson \& Hessen (1991), although slightly lower, and show little variability. CV: coefficient of variability

\begin{tabular}{|lccc|}
\hline $\mathrm{C}(\mu \mathrm{mol})$ & $\mathrm{P}(\mu \mathrm{mol})$ & & C:P ratio \\
\hline 180 & 3.48 & & 52 \\
297 & 5.73 & & 52 \\
248 & 4.83 & & 51 \\
388 & 7.17 & & 54 \\
275 & 4.93 & & 56 \\
172 & 3.79 & & 45 \\
362 & 5.92 & & 61 \\
277 & 4.91 & Mean & 57 \\
317 & 5.65 & Range & 54 \\
& & CV & 8 \\
& & & 84 \\
& & & \\
\hline
\end{tabular}

individual Daphnia spp. failed because of low $\mathrm{C}$ mass of individuals.

In an effort to analyze individual samples for $\mathrm{C}, \mathrm{P}$, and $\mathrm{N}$, a limited number of samples were taken and the persulfate digested portion was redigested in basic persulfate following the method of D'Elia et al. (1977) (Fig. 4). Although, in the 0.25 to $3.0 \mu \mathrm{mol}$ range tested, the results were linear and the intercept of the regression of basic persulfate as a function of persulfate/basic persulfate was not significantly different from $0(0.03 \pm$ $0.07[\mathrm{SE}])$, the slope of the line was greater than $1(1.15 \pm 0.05$ [SE]). This indicates that 10 to $20 \%$ of the $\mathrm{N}$ is lost during the initial digestion, possibly through volatilization. Recovery of some of this may be possible during the $\mathrm{C}$ analysis step using a $\mathrm{GC}$ capable of detecting $\mathrm{N}_{2}$ and $\mathrm{N}_{2} \mathrm{O}$.

\section{DISCUSSION}

Since C:P ratios are so important in understanding aquatic food webs, our simple, efficient, yet inexpensive technique that analyzes particulate $\mathrm{P}$ and $\mathrm{C}$ without the use of separate samples should be useful to many researchers. We have found only 2 other methods for measurement of particulate $\mathrm{P}$ and $\mathrm{C}$ on the same sample in the literature. The earlier technique by Malley et al. (1993) is limited by the need for a very expensive near-infrared reflectance spectrophotometer. The recent method by Raimbault et al. (1999)

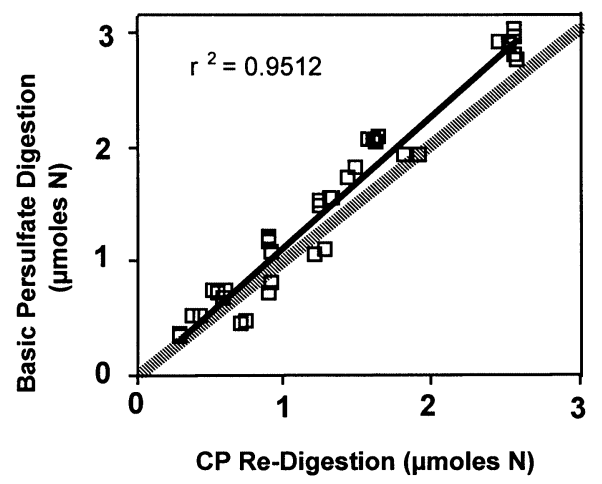

Fig. 4. Comparison of replicate filtered samples run using a standard basic persulfate digestion of D'Elia et al. (1977) with redigestion of previously digested $1 \%$ persulfate samples handled as for C:P analysis. The regression line is $y=1.15 x-0.027 ; r^{2}=0.95$ 
uses a new wet oxidation procedure for the simultaneous digestion of $\mathrm{C}, \mathrm{N}$, and $\mathrm{P}$. Although $\mathrm{C}$ and $\mathrm{N}$ may be completely oxidized by this method, we found this technique to inefficiently hydrolyze both polyphosphate standards and natural estuarine seston samples. Since some phytoplankton can contain polyphosphate (Kuhl 1962), an inefficient digestion may result in substantial errors in C:P ratios.

Errors in C:P ratios can also occur when replicate samples are run separately for $C$ and $P$, which is true when $\mathrm{C}$ is run using dry combustion and $\mathrm{P}$ is analyzed separately using a wet digestion. The error resulting from nonmatched $\mathrm{C}$ and $\mathrm{P}$ samples are most severe when there is large variation in $\mathrm{C}$ and $\mathrm{P}$ content between samples. For zooplankton samples this error can be particularly large because, even with a matched number of zooplankton per sample, the size of zooplankton can cause substantial differences in $\mathrm{C}$ and $\mathrm{P}$ content per sample. For example, for 9 replicate samples of zooplankton with 10 zooplankton per sample (Table 3), the CV for C and P was 26 and $22 \%$, respectively, but was only $8 \%$ for $\mathrm{C}: \mathrm{P}$ ratios on matched samples. On the other hand, when we randomly matched $\mathrm{C}$ and $\mathrm{P}$ replicates, which would be true for separate analysis of $\mathrm{C}$ and $\mathrm{P}$ samples, the $\mathrm{CV}$ of $\mathrm{C}: \mathrm{P}$ ratios increased to $37 \%$. For well replicated samples this increase in variance should be far less. For example, for the well mixed diatom sample (Table 2), $\mathrm{CV}$ for C:P ration increased only from 2.1 to $3.9 \%$ when we randomly matched filter pairs. For seston samples with moderate between-sample variation the problem of errors generated from nonmatched samples are likely intermediate between these 2 extremes.

Another advantage of the $1 \%$ persulfate method over others is the cost associated. Equipment and materials costs as well as time can be reduced by using this method. For example, the cost of a Carlo-Erba CN analyzer exceeds $\$ 30000$, and the per-sample analysis cost is approximately $\$ 3.80$. For the GC method, equipment costs are less than $\$ 8000$ and per-sample analysis costs just over $\$ 0.50$. The preparation and analysis rate for both methods is roughly 8 to 12 samples $\mathrm{h}^{-1}$, but if phosphorus is also to be run, substantial time is saved by using the GC method since the samples have already been digested for that analysis.

The use of persulfate digestion to oxidize organic materials has been widely accepted in aquatic research. When we compare our adaptation of this with the other accepted methods the results are indistinguishable. On phytoplankton and seston samples in the range of 1 to $40 \mu \mathrm{mol}$ and digested in $1 \%$ persulfate, both $\mathrm{P}$ and $\mathrm{C}$ are oxidized as completely as through the use of high temperature combustion. Further, C sample replication was found to be more precise with this procedure. The relatively low cost of the equipment and sample analysis make this method useful for the numerous determinations necessary to characterize the $\mathrm{C}: \mathrm{P}$ ratios in aquatic communities.

Acknowledgements. This is a contribution to the Institute of Ecosystem Studies. Financial support was provided by the Hudson River Foundation, the National Science Foundation, and New York State Sea Grant.

\section{LITERATURE CITED}

Abdel-Moati AR (1990) Adsorption of dissolved organic carbon (DOC) on glass fiber filters during particulate organic carbon (POC) determination. Water Res 24:763-764

Alpkem Corporation (1992) The flow solution operation manual. Method \#001094. The Corporation, Wilsonville, Oregon

American Public Health Association (1992) Standard methods for the examination of water and waste water, 18th edn. The Association, New York

Anderson JM (1976) An ignition method for determination of total phosphorus in lake sediments. Water Res 10:329-331

Anderson T, Hessen DO (1991) Carbon, nitrogen and phosphorus content of freshwater zooplankton. Limnol Oceanogr 36:807-814

Caraco NF, Miller R (1998) Effects of $\mathrm{CO}_{2}$ on competition between cyanobacterium and eukaryotic phytoplankton. Can J Fish Aquat Sci 55:54-62

D'Elia FP, Steudler A, Corwin N (1977) Determination of total nitrogen in aqueous samples using persulfate digestion. Limnol Oceanogr 22:760-764

Elser JJ, Chrzanowski TH, Sterner RW, Mills KH (1998) Stoichiometric constraints on food-web dynamics: a wholelake experiment on the Canadian Shield. Ecosystems 1: 120-136

Gordon DD Jr, Sutcliffe WH Jr (1974) Filtration of seawater using silver filters for particulate nitrogen and carbon analysis. Limnol Oceanogr 19:989-993

Hilton J, Lishman JP, Mackness S, Heaney SI (1986) An automated method for the analysis of 'particulate' carbon and nitrogen in natural waters. Hydrobiologia 141: $269-271$

Jingfeng WW, Sunda W, Boyle EA, Karl DM (2000) Phosphate depletion in the Western North Atlantic Ocean. Science 289:759-762

Kuhl A (1962) Inorganic phosphorus uptake and metabolism. In: Lewin RA (ed) Physiology and biochemistry of algae. Academic Press, New York, p 211-229

Maciolek JA (1962) Limnological organic analyses by quantitative dichromate oxidation. Res Rep US Fish Wildl Serv 60

Malley DF, Williams PC, Stainton MP, Hauser BW (1993) Application of near-infrared reflectance spectroscopy in the measurement of carbon, nitrogen, and phosphorus in seston from oligotrophic lakes. Can J Fish Aquat Sci 50: 1779-1785

McDowell WH, Cole JJ, Driscoll CT (1987) Simplified version of the ampoule-persulfate method for determination of dissolved organic carbon. Can J Fish Aquat Sci 44: $214-218$

Menzel DW, Corwin N (1965) The measurement of total phosphorus in sea water based on the liberation of organically bound fraction by persulfate oxidation. Limnol Oceanogr $10: 280$ 
Menzel DW, Vaccaro RF (1964) The measurement of dissolved organic and particulate carbon in seawater. Limnol Oceanogr 9:138-142

Murphy J, Riley JP (1962) A modified single solution method for the determination of phosphate in natural waters. Anal Chim Acta 27:31-36

Nakajima K (1986) Determination of particulate organic carbon in waters by the chemical oxidation method. Water Res 20:1407-1410

Raimbault P, Diaz F, Pouvesle W, Boudjellal B (1999) Simultaneous determination of particulate organic carbon, nitrogen and phosphorus collected on filters, using a semiautomatic wet-oxidation method. Mar Ecol Prog Ser 180: 289-295

Redfield AC (1958) The biological control of chemical factors in the environment. Am Sci 46:205-221

Sambrotto R, Savidge G, Robinson C, Boyd P, Takahashi T (1993) Elevated consumption of carbon relative to nitrogen in the surface ocean. Nature 363:248-250

Sharp JH (1974) Improved analysis for 'particulate' organic

Editorial responsibility: Otto Kinne (Editor),

Oldendorf/Luhe, Germany carbon and nitrogen from seawater. Limnol Oceanogr 19: 984-989

Stainton MP (1973) A syringe gas-stripping procedure for gas-chromatographic determination of dissolved inorganic and organic carbon in freshwater and carbonates in sediments. J Fish Res Board Can 30:1441-1445

Sterner RW, Elser JJ, Fee EJ, Guilford SJ, Chrzanowski TH (1997) The light:nutrient ratio in lakes: The balance of energy and materials affects ecosystem structure and process. Am Nat 150:663-684

Strickland JDH, Parsons TR (1968) A manual for sea water analysis. Bull Fish Res Board Can 167

von Stosch HA, Drebes G (1964) Entwicklungsgeschichtliche Untersuchungen an zentrischen Diatomeen. IV. Die Planktondiatomeen Stephanopyxis turris-ihre Behandlung und Entwicklungsgeschichte. Helgol wiss Meeresunters 11:209-257

Wangersky PJ, Gordon DC Jr (1965) Particulate carbonate, organic carbon and $\mathrm{Mn}^{++}$in the open ocean. Limnol Oceanogr 10:544-550

Submitted: September 1, 2000; Accepted: December 12, 2000 Proofs received from author(s): June 28, 2001 